\title{
Perspectives on working memory: introduction to the special issue
}

\author{
Robert H. Logie • Nelson Cowan
}

Published online: 24 March 2015

(C) Psychonomic Society, Inc. 2015

\begin{abstract}
More than 40 years ago, Baddeley and Hitch (1974) published an article with a wealth of experimentation and theorization on working memory, the small amount of information held in mind and often used within cognitive processes such as language comprehension and production, reasoning, and problem solving. We honor this seminal accomplishment in the present special issue, and take this opportunity to provide an introduction to our perspectives on the origin of the theory of working memory, how it has affected our work, what may be coming in the near future, and how the research articles in the present issue contribute to several related themes within the clearly thriving field of working memory.
\end{abstract}

Keywords Working memory · Short-term memory · Attention · Intelligence

We suspect that not many scientific topics appeal to both philosophically minded and practically minded researchers, but such is the case for the topic of working memory, famously articulated in a long chapter by Baddeley and Hitch (1974; henceforth $\mathrm{BH}$ ) within a book series, The Psychology of Learning and Motivation. The purpose of the present journal issue is to honor the authors of that work on its 40th anniversary, to celebrate the work itself, and to illustrate by example

R. H. Logie $\cdot$ N. Cowan

University of Edinburgh, Edinburgh, UK

N. Cowan

University of Missouri, Columbia, Missouri, USA

R. H. Logie $(\square)$

Department of Psychology, University of Edinburgh, 7 George

Square, Edinburgh EH8 9JZ, UK

e-mail: rlogie@staffmail.ed.ac.uk some of the many lines of research it has influenced. In the present introductory article, we hope to provide some perspective and to describe where we have come from as a field, as well as to suggest where the field might go in the near future.

Not many psychologists working in 1974 would have predicted the widespread effects of that chapter by $\mathrm{BH}$, which has been cited almost 10,000 times in the scientific literature. It contained many previously unpublished experiments, a broad and extensive literature review, and the emergence of an exciting new theory. Now, 40 years later, one can find many cognitive psychologists vigorously debating the details of the theory, neuroscientists debating its physical implementation, and a wide range of applied scientists and practitioners debating the roles of working memory in education, in the workplace, and in various disabling cognitive and neurologic conditions. Truly, it has been one of the most influential works in the field of cognitive science.

Working memory can be defined as the holding mechanism in the mind for a small amount of information that is kept in a temporarily heightened state of availability. As such, it should contain what we think of as the conscious mind, but also captures the broader role of ongoing processing and temporary memory functions outside of conscious awareness. It can be contrasted with the vast amount of information in one's long-term memory system, most of which can be retrieved only when the right cues emerge. The holding mechanism, which is probably compound rather than a single mechanism, is called working memory because it is essential for doing the work of cognition. The work comprises such things as holding on to phonemes and words in speech until they can be recalled in the correct order or be integrated into meaningful ideas; temporary storage of visual properties of objects such as shape, color, or location, and of sequences of arm or body movements to aid actions; holding on to the key information needed to figure out the solution to a problem; supporting mental imagery; and holding on to our immediate plans until 
we can carry them out. Working memory is needed for both our understanding of problems and our production of solutions, for both acting in and navigating around the world, and for both the comprehension and production of language. Several of these topics are represented in the articles for this special issue.

$\mathrm{BH}$ emphasized the point that previous theories had included a temporary holding mechanism focused largely on verbal material and had assumed too much about the capabilities of that single mechanism. What people held in mind while reasoning would have to conflict with the need to hold in mind some unrelated words in a single holding mechanism, but the observed amount of conflict was much less than one would expect from a unified mechanism, and what conflict had been observed was insensitive to changes in the complexity of the concurrent reasoning task. There was also much less conflict than one would expect between the need to hold a verbal set of items while processing a spatially arranged nonverbal set, or vice versa; by the same token, there was much more conflict when two sets of materials of the same kind needed to be dealt with. For these reasons, BH discussed the fractionation of the holding mechanism into several parts. They had much discussion of a specialized articulatory loop, later (Vallar \& Baddeley, 1984) known as the phonological loop, and a less well-worked-out analogous system for holding visual, spatial information, subsequently (Baddeley, 1983) called the visuo-spatial sketchpad. BH also recognized a dedicated subsystem making the whole system work, by shuttling information as appropriate from one dedicated store to another and making processing decisions; it was called the central executive.

To celebrate the work is not to express total agreement with it. In fact, both Baddeley and Hitch themselves have offered revisions of their work over the years (e.g., Baddeley, 1986, 2000, 2012; Burgess \& Hitch, 1999). Researchers coming from different backgrounds or interests often tend to emphasize different aspects of the 1974 chapter or to agree more strongly with some parts than with others. There is also a tendency for some researchers to attribute contents to the 1974 chapter that it did not include and that were developed much later (e.g., in Baddeley, 1983, 1986; for a recent review and commentary, see Logie, in press).

In order to help promote a general understanding of the development of the field of working memory stemming from the seminal chapter of $\mathrm{BH}$, we (Logie and Cowan) present two different personal perspectives on how we view this development. Then we examine some fascinating history behind the field of working memory, briefly look toward the future of the field inspired by $\mathrm{BH}$, and finally provide a quick preview of the contributions of the following articles in this issue.

\section{Working memory observations I: Robert Logie}

My interest in working memory was inspired by a fascination with the phenomena of visual imagery, visual imagery mnemonics, and the temporary retention of visual information such as color, size, and shape, and of spatial information such as location, movement, and navigation. It was also inspired by Zenon Pylyshyn, writing in 1973, who argued that not all functional mental operations are necessarily conscious, and not all conscious experience is necessarily functional. I had a particular problem with the question of conscious control that suggested some form of homunculus that was in overall charge of cognition, because this raises the obvious question of what controls the homunculus, and so on, leading to an unhelpful infinite regress. For me, the concept of consciousness (and with it, the concept of attention to mental processes) was too vague and was subject to the biases of introspection, and it got in the way of understanding mental operations, many of which might not be readily accessible to consciousness. If anything, consciousness was linked with attention to and interactions with the external world through perception and action, but reflected only the product, not the function, of multiple, parallel, and largely nonconscious mental operations that processed, encoded, stored, and retrieved: an artifact of operations in the mental factory that gives only indirect and imprecise indications of how those mental operations go about their business. The experience of mental imagery was then the conscious "noise outside the factory" that was related to, and perhaps correlated with - but not necessarily an accurate reflection of - the mental operations in tasks attributed to imagery, such as mental rotation, mental scanning, or judging the relative sizes of animals when presented with their names (e.g., Kosslyn, Ball, \& Reiser, 1978; Paivio, 1975). This view was reinforced when running experiments during my $\mathrm{PhD}$ research (Logie, 1981) and finding that subjective reports of mental operations during imagery and visual memory tasks often did not match the data patterns from the tasks that participants were performing.

Since the late 1980s, Cowan has contributed a great deal to our understanding of the relationship between conscious attention and those aspects of working memory that are available to conscious experience (e.g., Cowan, 1988, 2005). As he notes below, it might be difficult to understand how consciousness could be divided, although split-brain patients might offer an exception (e.g., Gazzaniga, 1967). There seems to be less conceptual difficulty with the possibility of dividing mental operations that are supported by multiple, domain-specific, nonconscious processes that can operate in parallel and in concert, even if that possibility does not reflect our personal mental experience. An analogy is found from studies of insect colonies, in which specific groups of insects each have specific roles to perform, and these different groups interact in particular ways. The functioning of the colony as a whole is then 
an emergent property of the multiple, interacting parallel activities, as indeed is the appearance of executive control (e.g., Willshaw, 2006). One formal model of working memory built broadly on this concept was proposed as consisting of interacting cognitive subsystems (Barnard, 1999). In this kind of model, the organization of working memory arises from multiple, cognitive subsystems, each with a specific role for storage and/or processing, working together to perform a given task. The extent to which each cognitive resource is recruited is driven by the demands of the current task, with some resources working at maximum capacity, and others contributing well within their operational limits. Executive control arises from the way in which these systems interact. This approach has yet to be fully explored empirically, but it does offer a range of testable hypotheses and the prospect of removing the problem of infinite regress when attempting to explain the subjective experience of conscious control.

$\mathrm{BH}$ mentioned the idea of a temporary visual store only in passing, although it was the empirical focus of two subsequent book chapters (Baddeley, Grant, Wight, \& Thomson, 1975; Baddeley \& Lieberman, 1980). The broad concept of a visuospatial sketchpad was first proposed by Baddeley (1983, 1986), for whom this mechanism was assumed primarily to be a spatial processing and memory system, supporting mental imagery, and linked to the control of movement. During the early 1980s, I had the opportunity and privilege to work as a postdoctoral researcher with Alan Baddeley at the Medical Research Council Applied Psychology Unit (now the Cognition and Brain Sciences Unit) in Cambridge, UK. He encouraged my independent exploration of the visuo-spatial sketchpad, which offered a framework for generating and testing hypotheses regarding my own interests in visual imagery and short-term visual memory.

For most of the three decades after the 1974 chapter, Baddeley and Hitch each focused largely on the development of the concept of the articulatory (later phonological) loop for verbal short-term memory, which had also been their original focus. Theories of control systems or executive resources continued to develop (Baddeley, 1986, 1996; Baddeley \& Logie, 1999), but the concept of the visuo-spatial component of the BH framework remained largely underexplored and underdeveloped (although see, e.g., Hitch, Halliday, Schaafstal, \& Schraagen, 1988). I gained initial encouragement from some experiments of my own (Logie, 1986) that demonstrated selective interference of irrelevant visual perceptual input, but not of presentation of irrelevant speech, with the use of a visual imagery mnemonic. This finding was complemented by the observation that irrelevant speech, but not irrelevant visual input, selectively interfered with verbal free recall. This experimental double dissociation suggested that the hypothesized visuo-spatial sketchpad could handle visual as well as spatial representations, and that it was dissociable from the functions of temporary verbal memory. A similar pattern of this kind of domain-specific double dissociation between visuo-spatial and verbal working memory was reported by Logie, Zucco, and Baddeley (1990), except that, in addition to the substantial domain-specific interference, they found evidence of a smaller, domain-general involvement in the carrying out of two concurrent demanding tasks. This general theme of identifying the domain-specific and domaingeneral components of working memory has been a feature of much of my subsequent research on working memory (e.g., Cocchini, Logie, Della Sala, MacPherson, \& Baddeley, 2002; Law, Trawley, Brown, Stephens, \& Logie, 2013; Logie, 1995, 2003, 2011; Logie, Cocchini, Della Sala, \& Baddeley, 2004; Logie, Trawley, \& Law, 2011). The general idea is that when task demands can be met within the capacity of domainspecific resources, they work in concert for task completion. However, when the task demands exceed the capacity of domain-specific resources, then domain-general resources are recruited. The conclusion from the Logie et al. (1990) study was that domain-specific and domain-general resources both contribute to tasks that impose a high cognitive load. This was broadly consistent with the conclusion from $\mathrm{BH}$ that when temporary memory is overloaded, it can be supplemented by control processes. Recently, this general theme has been followed up by Cowan, Saults, and Blume (2014), who refer to central and peripheral components of working memory, thereby suggesting a gradual convergence between our views.

Subsequent studies of the visuo-spatial sketchpad have suggested that the original concept was too broad and allencompassing. Its role in mental imagery appeared to be associated with visual perception and the control of visual attention, as well as being linked with conscious experience. These functions appeared to be rather different from temporary memory for visual features, which was now attributed to a "visual cache" (Logie, 1995), argued to be a nonconscious temporary visual memory system separate from conscious mental imagery (e.g., Borst, Niven, \& Logie, 2012; Logie, Della Sala, Beschin, \& Denis, 2005; Parra, Della Sala, Logie, \& Morcom, 2014; van der Meulen, Logie, \& Della Sala, 2009). The contents of this temporary visual memory system would be available to consciousness only when items were being encoded or retrieved or mentally rehearsed.

Whereas my own work has focused on the further development of ideas on visuo-spatial working memory, Baddeley and colleagues attributed some of the original assumed functions of the visuo-spatial sketchpad to a new hypothesized component of working memory, the episodic buffer (Baddeley, 2000), that is thought to retain integrated temporary representations. However, the original assumption that the episodic buffer concept required the control of attention in order to form and retain temporary bindings between different stimulus features appears not to have been supported empirically. Temporary binding of, for instance, shape and color appears to be largely automatic (e.g., Allen, Baddeley, 
\& Hitch, 2006), and some of its characteristics do appear similar to those of a domain-specific temporary visual memory system. However, the precise relationship between the episodic buffer, visual short-term memory, and visual imagery has yet to be explored in detail.

Finally, I was heavily influenced by research during the 1970s and 1980s in the UK and in Italy, involving collaborations between cognitive psychologists and neurologists that led to clear evidence of brain-damaged individuals with selective deficits in verbal short-term memory, but with intact visual short-term memory and largely intact executive and longterm memory functions (e.g., Vallar \& Baddeley, 1984; Warrington \& Shallice, 1972). Other brain-damaged individuals had been reported with converse deficits (e.g., De Renzi \& Nichelli, 1975; Warrington \& Rabin, 1971)-namely, impaired visual short-term memory and intact verbal short-term memory, again with intact executive functions and long-term memory. BH had drawn on some of this early research on selective impairments in their review of research offering additional, converging evidence for their proposal of a separation between verbal short-term memory, visual short-term memory, and higher-level executive functions, as well as separation between all of these functions and long-term memory. Reports of selective deficits in working memory coupled with intact access to long-term memory also undermined previous assumptions that working memory acted as a gateway between sensory input and long-term memory (e.g., Atkinson \& Shiffrin, 1968; Broadbent, 1958): If the gateway is damaged, this should compromise long-term memory access, but this was clearly not the case.

In the spirit of the BH question "what is short-term memory for?," the experimental studies cited above offer examples of theoretical insight into the functioning and cognitive architecture of a multiple-component working memory in the healthy brain (Logie, 2011), whereas the selective nature of the deficits in patients, coupled with the theoretical understanding of healthy young and aging brains, offers both aids for diagnosis and a basis for targeting the kinds of specific help that such patients require in their daily lives (for reviews, see Della Sala \& Logie, 1993; Logie \& Della Sala, 2005; Logie, Horne, \& Pettit, 2015).

\section{Working memory observations II: Nelson Cowan}

I am in broad agreement with Logie, but come from a different background with a different emphasis. Since high school, I had hoped to do research to find out more about the nature of human conscious experience. I also wanted this research to be of use clinically. Working memory satisfies both aims, since it presumably must include all of the information that is consciously accessible, and probably other information that is especially accessible to consciousness, even if not fully in consciousness. Working memory very much helps to define one's cognitive capabilities and limitations.

In this section, I will comment on what BH said, which sometimes differs from how BH is remembered, and the importance of what they said for my own thinking. First, I must explain my outlook. Any part of working memory that is accessible to consciousness intuitively would seem to have to be unitary in nature; consciousness cannot have parts that do not know about each other. This intuition is embodied in the hypothesis of Baars (1988) that working memory serves as a global workspace, and it also is implicit in the notion of the focus of attention as a core holding facility (Cowan, 1988). The central core of working memory would incorporate and synthesize information from many different modalities and codes (both sensory and semantic) to arrive at an overall conception of the environment and of one's current situation. It is closely related to what Baddeley (2000) later called the "episodic buffer." One might then ask whether a central core of working memory maps onto the theoretical views of BH. I think it does.

It is often emphasized that $\mathrm{BH}$ fractionated working memory, noting the need for specialized stores for different kinds of information; that, indeed, might be their key theoretical contribution. They showed that the trade-off between different processes was too small to fit the assumption that everything was handled by a single, capacity-limited mechanism. It is often assumed, though, that BH abandoned the idea of a central holding store entirely, and that is not the case. They said, for example (pp. 75-77),

We would like to suggest that the core of the working memory system consists of a limited-capacity "work space" which can be divided between storage and control processing demands. . . . Our data suggest that a tradeoff exists between the amount of storage required and the rate at which other processes can be carried out. .

.. We have suggested that the working memory system may contain both flexible work space and also a component that is dedicated to storage.

A bit later they appeared a little less certain, saying

It is clear that visual and auditory short-term storage do employ different subsystems. What is less clear is whether we need to assume completely separate parallel systems for different modalities, or whether the different modalities may share a common central processor.

They went on to describe preliminary evidence for the latter view.

The question of the contribution of a central store is a difficult one, because it is not clear how to quantify the amount of interference between two processes. Recent work may have made the situation clearer, because of the 
availability of some rudimentary models that express the number of items in working memory. Cowan, Saults, and Blume (2014) used such models and examined the amount of interference in working memory between a spatial array of colors and a list of verbal items. The finding was that the need to retain both sets reduced memory a bit; people remembered about one item fewer than they would if only separate, parallel stores were used. Basically, people remembered about three items per modality when each modality was to be retained alone, and about five (not six) items total when verbal and nonverbal modalities were to be retained together. The parallel storage ability was striking, given that verbal rehearsal was suppressed in these experiments. Nevertheless, a central storage mechanism was present, and its level of involvement could be viewed as being consistent with the suggestions of BH. Moreover, relevant to the episodic buffer notion, in experiments requiring the correct binding of color to shape, and of word to voice, different results were obtained. In unimodal retention, people could remember only about two visual or two verbal bound items. When trying to remember both at once, they could retain about three (not four) bound items total. To review, the concurrentstorage cost was about one item in both nonbinding and binding situations. Although this result is in keeping with what Allen et al. (2006) found, notice that a larger proportion of binding memory is dependent on the central, amodal part of working memory than is the case for singlefeatured items, which is possibly compatible with the episodic buffer notion of Baddeley (2000).

It also appears that the central storage component was viewed as trading off with executive processes. For example, BH (p. 77) noted,

Provided the memory load does not exceed the capacity of the phonemic buffer, little demand is placed upon the central executive, other than the routine recycling of the presumably familiar subroutines necessary for rehearsing digits. When the capacity of the phonemic buffer is exceeded, then the executive component of working memory must devote more of its time to the problem of storage. This probably involves both recoding in such a way as to reduce the length or complexity of the phonemic subroutine involved in rehearsal and also devoting more attention to the problem of retrieval.

This interpretation, however, makes it less clear whether the proposal includes not only processing but also a basic store that is general across modalities and codes, such as the focus of attention (Cowan, 1988) or the episodic buffer (Baddeley, 2000). In any case, this conception of a flexible part of the system can be seen as encouraging the use of the working memory framework to investigate individual differences in ability, which may depend on the efficiency of the allocation of the flexible resource (e.g., Conway, Kane, \& Engle, 2003; Daneman \& Carpenter, 1980).

BH concluded with quite a successful wish: "We began with a very simple question: what is short-term memory for? We hope that our preliminary attempts to begin answering the question will convince the reader, not necessarily that our views are correct, but that the question was and is well worth asking." Taken in this spirit, BH should not be viewed as proposing a full model of the information-processing system, but a rough-and-ready model that could be used to explain their results. By way of contrast, in an attempt to encompass the processing system (albeit with many gaps), I suggested that passive storage may consist in an activated portion of long-term memory (Cowan, 1988). It can include any number of different codes that people use (e.g., visual or auditory sensory, phonological, spatial, orthographic, tactile, tonal, or semantic). To account for similarity effects in interference between sets of items, one can propose that sets with more similar features interfere with each other more. To account for patients with a specific inability to use a memory code (e.g., the ability to speak and comprehend language, but not to remember much verbal information), perhaps one can propose a damaged link between the feature code and the memory system. I still included important parts of the BH conception (e.g., central executive processes and a low-effort, efficient verbal rehearsal process). So the attempt was to be more general, while necessarily allowing many gaps in the account to be filled in later. Nevertheless, the origin of this model was largely in $\mathrm{BH}$.

\section{The historical context for BH working memory}

None of us works in a vacuum. When we emphasize the novelty of the $\mathrm{BH}$ approach, our field should also try to become familiar with the debts we owe to previous researchers and other fields of research and try to appreciate those debts. This will avoid the risk of a perpetual cycle of ignoring and rediscovering previous findings and ideas, thereby enhancing rather than hampering the progress of science. A detailed discussion of the historical context of the "Seven Ages of Working Memory" was offered by Logie (1996). He noted that we can identify the progression of the working memory concept across several different schools of thought, starting with the philosopher John Locke (1690), who referred to "contemplation" as "keeping an idea actually in view," in contrast to the "storehouse of ideas," now referred to as long-term memory. Wundt (1873/1948) referred to "processes, fleeting occurrences, in continual flux and change." William James $(1890 / 1905)$ referred to temporary memory as "Primary Memory," and long-term memory as "Secondary Memory." Seventy years later, the British researcher 
Donald Broadbent (1958) referred to a short-term store acting as a limited-capacity system for controlling attention and as a temporary memory buffer between sensory input and longer-term memory. Waugh and Norman (1965) adopting the term Primary Memory to refer to a limitedcapacity temporary memory that could use rehearsal to transfer material into a longer-term Secondary Memory.

In 1956, the same year that George Miller's (1956) seminal work identified the possible capacity limit for a temporary holding system, Alan Newell and Herb Simon (1956) wrote about a computer program designed to carry out symbolic logic proofs, the logic theory machine. To perform this computation, it relied "heavily on heuristic methods similar to those that have been observed in human problem solving activity" (p. 1). They introduced the term working memory, as follows (p. 11): "There are two kinds of memories, working memories and storage memories. The major distinction - that all information to be processed must be brought in from the storage memories to the working memories and then returned-will be brought out clearly when we define the elementary IP's [information processes]." They also went on to explain executive routines-for example (p. 45), "In its first segment ... the executive routine reads a new expression that is presented to it for proof, and places it in a working memory." These ideas were clearly in the air, though perhaps more informally, in oral form than in the well-distributed written form that an experimental psychologist would encounter. Newell and Simon showed that by making the computer use flexible methods of processing, as humans do, humanlike logical exercises could be carried out. The term working memory was given passing mention by Miller, Galanter, and Pribram (1960), and was explored in detail by Atkinson and Shiffrin (1968), who developed Broadbent's (1958) ideas for including control processes for the selection of material to be retained in a temporary store and for longer-term learning, They proposed control processes that included encoding, rehearsing, manipulating, and retrieving, as well as storing, information on a temporary basis. Like Broadbent 10 years earlier, Atkinson and Shiffrin viewed working memory as a temporary work space that received information directly from sensory input, processed that information, and transferred some of the information into a long-term store.

The contribution of BH was to assemble and reason about a large amount of the relevant data from studies of people with selective brain damage, as well as from experimental work with healthy adults. Cowan (2014) discussed additional historical background and tied it to $\mathrm{BH}$, who articulated the components of working memory in a way that has shaped many of the prominent topics of debate ever since, such as the debate as to how much of working memory is domain-specific versus general across domains.

\section{Some new directions}

Advances inspired by $\mathrm{BH}$ are being made on various fronts. Some investigators have used mathematical modeling to make assumptions and predictions more precise. Some have used neuroimaging and electrophysiology to identify relevant regions that are involved in working memory, and lately, even to identify which stimuli are represented in those regions (e.g., Lewis-Peacock, Drysdale, Oberauer, \& Postle, 2012). Some of Cowan's own collaborative neuroimaging research has addressed a hard problem, the relation of processing to attention and consciousness. This has shown that at least one brain area, the intraparietal sulcus, is activated when there is a working memory load from either visual or verbal sources (Cowan et al., 2011; Li, Christ, \& Cowan, 2014; Majerus et al., 2014). This area reflects the involvement of the focus of attention not only in memory, but also in perception (Cowan, 2011). The focus of attention or episodic buffer might serve as a cauldron for the formation of new long-term memories (Cowan, Donnell, \& Saults, 2013). Some neuroimaging work by Logie and colleagues (Parra et al., 2014) has shown that when long-term learning is not involved, and when there is heavy reliance on working memory for color-shape binding, regions within the parietal, temporal, and occipital cortex are activated, but not regions within the prefrontal cortex or the medial temporal lobe.

\section{Contributions to this issue}

The approaches to working memory are even more varied than those represented in our own views. This variation itself highlights the substantial influence of $\mathrm{BH}$, with the concept of working memory being explored to address strikingly different research questions. The original motivation for $\mathrm{BH}$ was to address how temporary memory is used in everyday life, as well as to account for a wide range of experimental findings. As is clear from the reports in this special issue, now very many more experimental findings must be explained, and this has led to a wide range of theoretical assumptions and ways of thinking about and studying working memory. There is also the ongoing question of why we have a working memory system. By no means are all of the contemporary approaches to working memory represented here, but three broad themes are addressed.

One of the themes views working memory as synonymous with a general cognitive capacity for online cognition that differs between individuals and is correlated with measures of fluid intelligence. Here, the focus is on the factors that drive this correlation. The articles by Chow and Conway (2015) and Mella, Fagot, Lecerf, and de Ribaupierre (2015) both present evidence that multiple factors contribute to general working memory capacity, consistent with $\mathrm{BH}$, 
demonstrating that there are multiple cognitive abilities, and that not all measures of those abilities are strongly related to intelligence. Lilienthal, Rose, Tamez, Myerson, and Hale (2015) demonstrate that the ability to monitor the source of information is more important than the ability to inhibit irrelevant input in characterizing the difference between individuals with high and low general working memory capacity. Harrison, Shipstead, and Engle (2015) demonstrate the complementary finding that some items in the Raven's matrix measure of fluid intelligence are more closely related to working memory capacity than are other items in the test. Bleckley, Foster, and Engle (2015) reported that high working memory capacity participants use more demanding attention allocation strategies than low capacity participants, with the former more disrupted by a concurrent load.

A second theme is focused specifically on the relationship between visual perception, visual attention, and temporary memory for briefly presented visual information. Consistent with $\mathrm{BH}$, but less consistent with more recent variations of working memory (Baddeley, 2012; Logie, 1995, 2011) the general assumption in this literature is that visual short-term memory and visual working memory are broadly synonymous, but rarely is there cross-reference to the conception of working memory as a general cognitive capacity (or vice versa). The article by Pailian and Halberda (2015) goes some way toward an integration between contemporary views of the multiple-component concept of working memory, cognitive capacity, and visual temporary memory. They neatly demonstrate that a flicker change detection task can estimate both the contribution of general cognitive capacity and the capacity of a temporary visual memory system, identifying these as dissociable capacities. More embedded in the research specifically on visual working memory is the study by Donkin, Tran, and Le Pelley (2015), which addresses an ongoing debate about whether capacity for the temporary retention of visual arrays is determined by a limited number of slots for items in the array, or by a flexible resource that stores at progressively lower resolution as the amount of detail to be remembered increases. Their data present an important challenge to the assumptions of the slots model. The study by Han (2015) elegantly demonstrates that the contents of visual working memory act to reduce competition between stimuli to aid the identification of a visual target, and do not simply help direct visual attention to a possible target location. LaRocque et al. (2015) present evidence that visually presented items that are not in the focus of attention are retained in visual working memory, even if at a lower resolution than attended items. Moreover, there is no evidence that this can be explained by unattended items being retained preferentially in long-term memory, in contrast to the expectations of the authors. This raises the intriguing possibility that more is held in working memory than is within the focus of attention, and that attention is primarily required in order to retain the fine details of a visual stimulus. Indirectly, it also hints at the possibility that limitations on the focus of attention might be based on a limited number of slots, but that working memory has a broader storage capacity outside the focus of attention that is limited by the resolution of the visual representation. That is, both slots and resource models could be correct, but they address different aspects of visual working memory function. Finally, within this theme, Cottini et al. (2015) offer evidence that points to an advantage of bilingualism for children's ability to focus on the local details of a visual stimulus rather than its global overall appearance. Bilingual children appear to be better than monolingual children when it comes to inhibiting salient but nonrelevant aspects of a visual stimulus.

The third theme centers on temporary memory for serial order, with studies of factors that contribute. Temporal grouping has long been established as a major factor in enhancing performance in serial recall tasks. Spurgeon, Ward, Matthews, and Farrell (2015) demonstrate such temporal grouping effects in free recall tasks and argue that immediate serial recall and immediate free recall might not be as different as has previously been assumed, particularly for lists that are similar in length. This does raise the question of whether participants are choosing to use a serial recall strategy for shorter lists, even when they are instructed to use free recall, but with longer lists choose a strategy of free recall, even when they are instructed to use serial recall. In this way, the similarity might arise from participants' choices of recall strategies rather than from the use of a common cognitive system. This hypothesis would be interesting to explore in future research. Poirier, Saint-Aubin, Mair, Tehan, and Tolan (2015) report evidence for a contribution from the semantic properties of verbal items to the retention of the serial order of verbal lists. This contrasts with previous research on immediate serial recall, and with some models of serial order that have assumed a long-term memory contribution to memory for items, but not for order. Tanida, Ueno, Lambon-Ralph, and Saito (2015) continue with this theme by demonstrating contributions from phonotactic and lexical prosody held in long-term memory to the retention of sets of Japanese materials.

An important further issue to consider in the studies above is the extent to which the paradigm chosen creates opportunities for contributions from item-specific information in longterm memory through the use of a large word pool, with different words being used across lists within experiments on serial recall. It would be interesting to explore these same paradigms while using items drawn from a small word pool, with the same items being repeated across lists in different orders. This would then focus on memory for order while reducing the possible contribution from long-term memory. Two further articles in this special issue are based on precisely this manipulation. Taylor, Macken, and Jones (2015) used lists of letters drawn from a limited set and demonstrated that the 
way that letters are habitually pronounced, specifically regarding linguistic stress, contributes to serial recall performance. This perhaps echoes some of the effects of temporal grouping explored by Spurgeon et al. (2015). Lin, Chen, Lai, and Wu (2015) used a limited set of Chinese characters and demonstrated that both the phonological and orthographic similarity of the items resulted in poorer probed serial recall performance than occurred when the items were phonologically or orthographically distinct. Both of these studies suggest that the physical characteristics of stimuli affect immediate memory for serial order. Future research might consider manipulating the size of the item pool to investigate systematically the effects of pool size on immediate serial recall.

The final article, by Allen and Waterman (2015), also addresses serial order, but focuses on the relatively underresearched task of remembering instruction sequences, and how different aspects of working memory contribute to this important everyday task. Their results point to the role of a possible action-motoric component of working memory that supports memory for action sequences.

It is clear from the articles included in this special issue that different research groups use the concept of working memory in very different ways. That the use of the working memory concept is so diverse and continues to be deployed, over four decades since its inception, attests to its theoretical and empirical utility. One of the many strengths of $\mathrm{BH}$ was that their framework offered a coherent account for a broad range of empirical findings. The collation in a single special, themed issue of such diverse contemporary and high-quality research on working memory illustrates the longevity of that concept, though it also highlights a need for new efforts to achieve and maintain theoretical coherence across this diversity of investigations. On the basis of the present articles, we are awed by what might be achieved in 40 more years of research linking a person's current mental state and ongoing cognition to the retention and combination of recent thoughts.

\section{References}

Allen, R. J., Baddeley, A. D., \& Hitch, G. J. (2006). Is the binding of visual features in working memory resource-demanding? Journal of Experimental Psychology: General, 135, 298-313. doi:10.1037/ 0096-3445.135.2.298

Allen, R. J., \& Waterman, A. H. (2015). How does enactment affect the ability to follow instructions in working memory? Memory \& Cognition, 43. doi:10.3758/s13421-014-0481-3

Atkinson, R. C., \& Shiffrin, R. M. (1968). Human memory: A proposed system and its control processes. In K. W. Spence \& J. T. Spence (Eds.), The psychology of learning and motivation: Advances in research and theory (Vol. 2, pp. 89-195). New York, NY: Academic Press.

Baars, B. J. (1988). A cognitive theory of consciousness. Cambridge, UK: Cambridge University Press.
Baddeley, A. D. (1983). Working memory. Philosophical Transactions of the Royal Society B, 302, 311-324. doi:10.1098/rstb.1983.0057

Baddeley, A. (1986). Working memory. Oxford, UK: Oxford University Press, Clarendon Press.

Baddeley, A. (1996). Exploring the central executive. Quarterly Journal of Experimental Psychology, 49A, 5-28. doi:10.1080/ 027249896392784

Baddeley, A. D. (2000). The episodic buffer: A new component of working memory? Trends in Cognitive Sciences, 4, 417-423. doi:10. 1016/S1364-6613(00)01538-2

Baddeley, A. (2012). Working memory: Theories, models, and controversies. Annual Review of Psychology, 63, 1-29. doi:10.1146/ annurev-psych-120710-100422

Baddeley, A. D., Grant, W., Wight, E., \& Thomson, N. (1975). Imagery and visual working memory. In P. M. A. Rabbitt \& S. Dornic (Eds.), Attention and performance $V$ (pp. 205-217). London, UK: Academic Press.

Baddeley, A. D., \& Hitch, G. J. (1974). Working memory. In G. H. Bower (Ed.), The psychology of learning and motivation: Advances in research and theory (Vol. 8, pp. 47-89). New York, NY: Academic Press.

Baddeley, A. D., \& Lieberman, K. (1980). Spatial working memory. In R. S. Nickerson (Ed.), Attention and performance VIII (pp. 521-539). Hillsdale, NJ: Erlbaum.

Baddeley, A. D., \& Logie, R. H. (1999). Working memory: The multiple component model. In A. Miyake \& P. Shah (Eds.), Models of working memory (pp. 28-61). New York: Cambridge University Press.

Barnard, P. J. (1999). Interacting cognitive subsystems: Modelling working memory pehnomena within a multiprocessor architecture. In A. Miyake \& P. Shah (Eds.), Models of working memory (pp. 298339). Cambridge, UK: Cambridge University Press.

Bleckley, M. K., Foster, J. L., \& Engle, R. W. (2015). Working memory capacity accounts for the ability to switch between object-based and location-based allocation of visual attention. Memory \& Cognition, 43. doi:10.3758/s13421-014-0485-z

Borst, G., Niven, E., \& Logie, R. H. (2012). Visual mental image generation does not overlap with visual short-term memory: A dual-task interference study. Memory \& Cognition, 40, 360-372. doi:10.3758/ s13421-011-0151-7

Broadbent, D. (1958). Perception and communication. Oxford, UK: Pergamon Press.

Burgess, N., \& Hitch, G. J. (1999). Memory for serial order: A network model of the phonological loop and its timing. Psychological Review, 106, 551-581. doi:10.1037/0033-295X.106.3.551

Chow, M., \& Conway, A. R. A. (2015). The scope and control of attention: Sources of variance in working memory capacity. Memory \& Cognition, 43. doi:10.3758/s13421-014-0496-9

Cocchini, G., Logie, R. H., Della Sala, S., MacPherson, S. E., \& Baddeley, A. D. (2002). Concurrent performance of two memory tasks: Evidence for domain-specific working memory systems. Memory \& Cognition, 30, 1086-1095. doi:10.3758/ BF03194326

Conway, A. R. A., Kane, M. J., \& Engle, R. W. (2003). Working memory capacity and its relation to general intelligence. Trends in Cognitive Sciences, 7, 547-552. doi:10.1016/j.tics.2003.10.005

Cottini, M., Pieroni, L., Spataro, P., Devescovi, A., Longobardi, E., \& Rossi-Arnaud, C. (2015). Feature binding and the processing of global-local shapes in bilingual and monolingual children. Memory \& Cognition, 43. doi:10.3758/s13421-014-0467-1

Cowan, N. (1988). Evolving conceptions of memory storage, selective attention, and their mutual constraints within the human information processing system. Psychological Bulletin, 104, 163-191. doi:10. 1037/0033-2909.104.2.163

Cowan, N. (2005). Working memory capacity. New York, NY: Psychology Press. 
Cowan, N. (2011). The focus of attention as observed in visual working memory tasks: Making sense of competing claims. Neuropsychologia, 49, 1401-1406. doi:10.1016/j.neuropsychologia. 2011.01.035

Cowan, N. (2014). Working memory underpins cognitive development, learning, and education. Educational Psychology Review, 26, 197223.

Cowan, N., Donnell, K., \& Saults, J. S. (2013). A list-length constraint on incidental item-to-item associations. Psychonomic Bulletin \& Review, 20, 1253-1258. doi:10.3758/s13423-013-0447-7

Cowan, N., Li, D., Moffitt, A., Becker, T. M., Martin, E. A., Saults, J. S., \& Christ, S. E. (2011). A neural region of abstract working memory. Journal of Cognitive Neuroscience, 23, 2852-2863. doi:10.1162/ jocn.2011.21625

Cowan, N., Saults, J. S., \& Blume, C. L. (2014). Central and peripheral components of working memory storage. Journal of Experimental Psychology: General, 143, 1806-1836. doi:10.1037/a0036814

Daneman, M., \& Carpenter, P. A. (1980). Individual differences in working memory and reading. Journal of Verbal Learning and Verbal Behavior, 19, 450-466. doi:10.1016/S0022-5371(80)90312-6

De Renzi, E., \& Nichelli, P. (1975). Verbal and nonverbal short term memory impairment following hemispheric damage. Cortex, 11, 341-353.

Della Sala, S., \& Logie, R. (1993). When working memory does not work: The role of working memory in neuropsychology. In F. Boller \& H. Spinnler (Eds.), Handbook of neuropsychology (Vol. 8, pp. 1-63). Amsterdam, The Netherlands: Elsevier.

Donkin, C., Tran, S. C., \& Le Pelley, M. (2015). Location-based errors in change detection: A challenge for the slots model of visual working memory. Memory \& Cognition, 43. doi:10.3758/s13421-0140487-x

Gazzaniga, M. S. (1967). The split brain in man. Scientific American, 217, 24-29.

Han, S. W. (2015). Working memory contents enhance perception under stimulus-driven competition. Memory \& Cognition, 43. doi:10. 3758/s13421-014-0460-8

Harrison, T. L., Shipstead, Z., \& Engle, R. W. (2015). Why is working memory capacity related to matrix reasoning tasks? Memory \& Cognition, 43. doi:10.3758/s13421-014-0473-3

Hitch, G. J., Halliday, S., Schaafstal, A. M., \& Schraagen, J. M. C. (1988). Visual working memory in young children. Memory \& Cognition, 16, 120-132. doi:10.3758/BF03213479

James, W. (1905). Principles of psychology (Vol. 1). London, UK: Methuen. Original work published 1890.

Kosslyn, S. M., Ball, T. M., \& Reiser, B. J. (1978). Visual images preserve metric spatial information: Evidence from studies of image scanning. Journal of Experimental Psychology: Human Perception and Performance, 4, 47-60.

LaRocque, J. J., Eichenbaum, A. S., Starrett, M. J., Rose, N. S., Emrich, S. M., \& Postle, B. R. (2015). The short- and long-term fates of memory items retained outside the focus of attention. Memory \& Cognition, 43. doi:10.3758/s13421-014-0486-y

Law, A. S., Trawley, S. L., Brown, L. A., Stephens, A. N., \& Logie, R. H. (2013). The impact of working memory load on task execution and online plan adjustment during multitasking in a virtual environment. Quarterly Journal of Experimental Psychology, 66, 1241-1258. doi: 10.1080/17470218.2012.748813

Lewis-Peacock, J. A., Drysdale, A. T., Oberauer, K., \& Postle, B. R. (2012). Neural evidence for a distinction between short-term memory and the focus of attention. Journal of Cognitive Neuroscience, 24, 61-79. doi:10.1162/jocn_a 00140

Li, D., Christ, S. E., \& Cowan, N. (2014). Domain-general and domainspecific functional networks in working memory. NeuroImage, 102, 646-656

Lilienthal, L., Rose, N. S., Tamez, E., Myerson, J., \& Hale, S. (2015). Individuals with low working memory spans show greater interference from irrelevant information because of poor source monitoring, not greater activation. Memory \& Cognition, 43

Lin, Y.-C., Chen, H.-Y., Lai, Y. C., \& Wu, D. H. (2015). Phonological similarity and orthographic similarity affect probed serial recall of Chinese characters. Memory \& Cognition, 43. doi:10.3758/s13421014-0495-x

Locke, J. (1690). An essay concerning humane understanding (Book II, Chapter X). London, UK: Taylor.

Logie, R. H. (1981). The symbolic distance effect: A study of internal psychophysical judgements. Unpublished doctoral dissertation, University College London, UK.

Logie, R. H. (1986). Visuo-spatial processing in working memory. Quarterly Journal of Experimental Psychology, 38A, 229-247. doi:10.1080/14640748608401596

Logie, R. H. (1995). Visuo-spatial working memory. Hove, UK: Erlbaum.

Logie, R. H. (1996). The seven ages of working memory. In J. T. E. Richardson, R. W. Engle, L. Hasher, R. H. Logie, E. R. Stoltzfus, \& R. T. Zacks (Eds.), Working memory and human cognition (pp. 31-59). New York, NY: Oxford University Press.

Logie, R. H. (2003). Spatial and visual working memory: A mental workspace. In D. Irwin \& B. H. Ross (Eds.), Cognitive vision: The psychology of learning and motivation (Vol. 42, pp. 37-78). New York, NY: Elsevier Science.

Logie, R. H. (2011). The functional organization and capacity limits of working memory. Current Directions in Psychological Science, 20, 240-245. doi:10.1177/0963721411415340

Logie, R. H. (in press). Working memory: Beyond Baddeley and Hitch's (1974) working memory. In M. W. Eysenck \& D. Groome (Eds.), Cognitive psychology: Revisiting the classic studies. Thousand Oaks, CA: Sage.

Logie, R. H., Cocchini, G., Della Sala, S., \& Baddeley, A. D. (2004). Is there a specific executive capacity for dual task co-ordination? Evidence from Alzheimer's Disease. Neuropsychology, 18, 504513.

Logie, R. H., \& Della Sala, S. (2005). Disorders of visuo-spatial working memory. In A. Miyake \& P. Shah (Eds.), Handbook of visuospatial thinking (pp. 81-120). New York, NY: Cambridge University Press.

Logie, R. H., Della Sala, S., Beschin, N., \& Denis, M. (2005). Dissociating mental transformations and visuo-spatial storage in working memory: Evidence from representational neglect. Memory, 13, 430-434.

Logie, R. H., Horne, M. J., \& Pettit, L. D. (2015). When cognitive performance does not decline across the lifespan. In R. H. Logie \& R. Morris (Eds.), Working memory and ageing (pp. 21-47). Hove, UK: Psychology Press.

Logie, R. H., Trawley, S., \& Law, A. S. (2011). Multitasking: Multiple, domain-specific cognitive functions in a virtual environment. Memory \& Cognition, 39, 1561-1574. doi:10.3758/s13421-0110120-1

Logie, R. H., Zucco, G. M., \& Baddeley, A. D. (1990). Interference with visual short-term memory. Acta Psychologica, 75, 55-74.

Majerus, S., Cowan, N., Péters, F., Van Calster, L., Phillips, C., \& Schrouff, J. (2014) Cross-modal decoding of neural patterns associated with working memory: Evidence for attention-based accounts of working memory. Cerebral Cortex. doi:10.1093/cercor/bhu189

Mella, N., Fagot, D., Lecerf, T., \& de Ribaupierre, A. (2015). Working memory and intraindividual variability in processing speed: A lifespan developmental and individual-differences study. Memory \& Cognition, 43. doi:10.3758/s13421-014-0491-1

Miller, G. A. (1956). The magical number seven, plus or minus two: Some limits on our capacity for processing information. Psychological Review, 63, 81-97. doi:10.1037/h0043158

Miller, G. A., Galanter, E., \& Pribram, K. H. (1960). Plans and the structure of behavior. New York, NY: Holt, Rinehart \& Winston. 
Newell, A., \& Simon, H. A. (1956). The logic theory machine: A complex information processing system. Santa Monica, CA: Rand Corp.

Pailian, H., \& Halberda, J. (2015). The reliability and internal consistency of one-shot and flicker change detection for measuring individual differences in visual working memory capacity. Memory \& Cognition, 43. doi:10.3758/s13421-014-0492-0

Paivio, A. (1975). Perceptual comparisons through the mind's eye. Memory \& Cognition, 3, 635-647.

Parra, M. A., Della Sala, S., Logie, R. H., \& Morcom, A. (2014). Neural correlates of shape-color binding in visual working memory. Neuropsychologia, 52, 27-36. doi:10.1016/j.neuropsychologia. 2013.09.036

Poirier, M., Saint-Aubin, J., Mair, A., Tehan, G., \& Tolan, A. (2015). Order recall in verbal short-term memory: The role of semantic networks. Memory \& Cognition, 43. doi:10.3758/s13421-0140470-6

Pylyshyn, Z. W. (1973). What the mind's eye tells the mind's brain: A critique of mental imagery. Psychological Bulletin, 80, 1-24. doi:10. 1037/h0034650

Spurgeon, J., Ward, G., Matthews, W. J., \& Farrell, S. (2015). Can the effects of temporal grouping explain the similarities and differences between free recall and serial recall? Memory \& Cognition, 43. doi:10.3758/s13421-014-0471-5

Tanida, Y., Ueno, T., Lambon-Ralph, M. A., \& Saito, S. (2015). The roles of long-term phonotactic and lexical prosodic knowledge in phonological short-term memory. Memory \& Cognition, 43. doi:10.3758/ s13421-014-0482-2
Taylor, J. C., Macken, B., \& Jones, D. M. (2015). A matter of emphasis: Linguistic stress habits modulate serial recall. Memory \& Cognition, 43. doi:10.3758/s13421-014-0466-2

Vallar, G., \& Baddeley, A. D. (1984). Fractionation of working memory: Neuropsychological evidence for a phonological short-term store. Journal of Verbal Learning and Verbal Behavior, 23, 151-161. doi:10.1016/S0022-5371(84)90104-X

van der Meulen, M., Logie, R. H., \& Della Sala, S. (2009). Selective interference with image retention and generation: Evidence for the workspace model. Quarterly Journal of Experimental Psychology, 62, 1568-1580. doi:10.1080/17470210802483800

Warrington, E. K., \& Rabin, P. (1971). Visual span of apprehension in patients with unilateral cerebral lesions. Quarterly Journal of Experimental Psychology, 23, 423-431. doi:10.1080/ 14640747108400254

Warrington, E. K., \& Shallice, T. (1972). Neuropsychological evidence of visual storage in short-term memory tasks. Quarterly Journal of Experimental Psychology, 24, 30-40. doi:10.1080/ 14640747208400265

Waugh, N. C., \& Norman, D. A. (1965). Primary memory. Psychological Review, 72, 89-104. doi:10.1037/h0021797

Willshaw, D. (2006). Self-organization in the nervous system. In R. G. M. Morris, L. Tarrassenko, \& M. Kenward (Eds.), Cognitive systems: Information processing meet brain science (pp. 5-33). London, UK: Academic Press.

Wundt, W. (1948). Principles of physiological psychology. In W. Dennis (Ed.), Readings in the history of psychology (pp. 248-250). New York, NY: Appleton-Century-Crofts. Original work published 1873. 